\title{
Gonzalo M. Borrás Gualis
}

El pasado 27 de febrero de 2019 nos dejó un grande entre los grandes de la Historia del Arte.

No resulta fácil plasmar en una nota, con la obligada brevedad de todo obituario, el resumen siquiera de sus enormes logros científicos y profesionales; no podemos mencionar aquí más que un puñado de los muchos méritos que acumuló a lo largo de una vida tan prolífica como la suya. Sabemos, sin embargo, que cualquiera de sus logros hablaría por sí mismo de la extraordinaria capacidad y el talento del profesor Borrás. Por eso, y porque en este momento no parece oportuno ni necesario, ni está ahora en nuestro ánimo el ser exhaustivos, queremos no obstante reseñar solo una pequeña parte de los que nos parecen pertinentes como testimonio de la trascendencia de su figura, ya sea desde una perspectiva académica, de investigación o de contribución a la defensa del patrimonio y en general al desarrollo de la ciencia y la cultura.

Hace no mucho tiempo, coincidiendo con el final de su carrera como docente, sus compañeros del departamento de Historia del Arte de la Facultad de Filosofía y Letras de la Universidad de Zaragoza publicaron un libro homenaje dedicado a él (Álvaro, Lomba y Pano, 2013). La introducción de dicha publicación, escrita por el profesor José Luis Pano Gracia, constituye una referencia esencial para quienes quieran conocer la hondura de los méritos del profesor Borrás más allá de esta escueta relación que ahora hacemos, cuya única pretensión es el intento de dejar constancia de la tristeza que sentimos por su pérdida desde la Universidad de Málaga, y en particular de quienes participamos en la edición de esta revista.

Nacido en 1940 y formado en la Universidad de Zaragoza, obtuvo en ella la cátedra de Arte Moderno y Contemporáneo en 1982, después de haber ejercido como profesor ayudante desde 1965, profesor adjunto entre 1970 y 1975 en dicha universidad, y como profesor agregado en la Autónoma de Barcelona desde 1976 a 1981.

En Zaragoza fue el primer director del departamento de Historia del Arte desde su creación en 1987 y fundador de la revista Artigrama, que había iniciado su andadura pocos años antes, en 1984. Alli ejercería la docencia hasta su jubilación en 2009, aunque seguiría vinculado como profesor emérito durante unos años más. Organizó y dirigió a lo largo de ese casi medio siglo de profesión infinidad de cursos de doctorado, másteres, congresos, seminarios, simposios, jornadas y ciclos de conferencias que sería imposible concretar aquí.

Aparte de su labor docente, con la que formó a generaciones de estudiantes y de no pocos futuros profesores en la comprensión del hecho artístico y de sus circunstancias históricas y sociales, la fecunda labor investigadora que desarrolló a lo largo de su vida estuvo vinculada a temáticas diversas (historia y arte medieval -musulmán y cristiano-, Renacimiento, Goya, Modernismo, arte contemporáneo...), pero sin duda son sus estudios sobre el mudéjar los que lo convirtieron desde muy temprano en una figura de primera línea, tanto a nivel nacional como internacional. Su tesis doctoral Mudéjar en los valles del Jalón-Jiloca (1971) fue una referencia para muchos otros investigadores, y base para la renovación critica de los estudios sobre el mudéjar, a los que siguió aportando brillantes trabajos a lo largo de toda su trayectoria profesional, siempre aparejados a la catalogación y difusión del patrimonio cultural. A modo de muestra cabe reseñar cómo su contribución a la valorización del universo artístico del mudéjar sería determinante en el reconocimiento e inclusión de la arquitectura mudéjar de Teruel (1986) y Zaragoza (2001) por parte de UNESCO en la Lista del Patrimonio Mundial.

Fruto de su constante labor investigadora es la calidad y el ingente número de publicaciones (Álvaro, Lomba y Pano, 2013: 25-44), con varios centenares de referencias de primer nivel de las que casi 50 son libros, algunos en colaboración y todos ellos imprescindibles. Al margen de la bibliografía del profesor Borrás referida al arte medieval, y en especial los trabajos relacionados con el universo mudéjar e islámico en general y con el arte aragonés, cabría destacar por su difusión los diccionarios de términos artísticos, 
los manuales de introducción al arte, de teoría y didáctica del arte, de historiografía artística en España, de metodología en la investigación histórico-artística y del patrimonio. Destacan también sus estudios sobre iconografía imperial o de artistas como Pontormo, Goya, Pablo Serrano, el Grupo Pórtico, etc, así como numerosas guías monumentales y artísticas, relacionadas a veces con los trabajos de inventario de bienes culturales que realizó. Fueron numerosos también los trabajos de dirección de memorias de licenciatura y tesis doctorales, y los proyectos de investigación que dirigió o en los que participó.

Obtuvo importantes galardones, tanto en lo académico como en el ámbito social, a destacar la Cruz de San Jorge de la Diputación Provincial de Teruel que recibió ya en 1979.

En el apartado de gestión habría que mencionar su participación y trabajo de dirección en instituciones culturales de tanto prestigio como el Instituto de Estudios Turolenses (Diputación Provincial de Teruel), al frente del cual estuvo durante una década entre mediados de los ochenta y los noventa, o ya en el siglo XXI el Instituto de Estudios Islámicos y del Oriente Próximo (Universidad de Zaragoza, CSIC y Cortes de Aragón), así como la Institución Fernando el Católico (Diputación Provincial de Zaragoza, adscrito al CSIC).

Mención aparte merece el compromiso con sus conciudadanos y especialmente en la defensa del patrimonio cultural, que se plasmó también en su actividad política, participando como candidato en diversos comicios y ejerciendo durante algún tiempo como teniente-alcalde de su ciudad, Zaragoza.

Decíamos al principio que no parecía fácil el resumen más o menos ordenado de algunos de sus trabajos y la referencia a una pequeña parte de sus publicaciones, o a los puestos de mayor relevancia académica o institucional que desempeñó, a la trascendencia que tuvo en general para la Historia del Arte como disciplina, así como para sus estudiantes, discípulos y compañeros de profesión en la universidad española y en el exterior, para el patrimonio en su tierra natal, Aragón, y por ende para la sociedad actual y futura gracias al legado de su buen hacer.

Pero mucho más difícil aún resulta el intento de plasmar las cualidades del hombre con el que tuve la suerte de coincidir (con la distancia entre maestro y aprendiz) en bastantes ocasiones, aunque no tantas como yo hubiera querido, pero sí todas en circunstancias que considero determinantes para mí por esa rara sensación que provoca la certeza de haber vivido la proximidad de una persona extraordinaria y un maestro.

Cualquier intento de homenaje por mi parte queda empequeñecido ante una personalidad de su talla, en lo profesional y en lo humano. Quienes tuvimos la fortuna de conocerlo, de disfrutar de su magisterio, de participar en las reuniones científicas organizadas por él o en los actos académicos o sociales donde estaba presente, no podremos olvidar mientras nos quede memoria la profundidad de sus análisis, la claridad de sus razonamientos, la elocuencia de sus palabras, lo certero de su juicio. Sin afectación alguna, con total naturalidad, hacía de cada situación, aun de aquellas que a priori nadie supondría fáciles, un motivo de ejercer la docencia en el sentido más amplio, una ocasión para aprender de él, y con él de nosotros mismos; cualquier ocasión era gracias a su intervención una oportunidad para el encuentro y una celebración por el descubrimiento de lo nuevo o la revisión de lo aparentemente ya sabido pero que merecía una segunda lectura; propiciaba siempre el intercambio de ideas con el interlocutor, al tiempo que movía tantas veces al auditorio a la sonrisa y la distensión sin mermar un ápice la solemnidad del acto si era el caso. Lo recuerdo trayendo a colación ya fuese en una clase, en sus conferencias o presentaciones, en una visita o en el contexto de una conversación amistosa las lecciones recibidas de sus maestros, los hallazgos de otros investigadores -citados con nombre y apellidos, incluso de los principiantes...- haciéndonos ver que somos todos un eslabón más en la cadena de la construcción del conocimiento. O relatando anécdotas que nunca eran banales, sino glosa genial de un concepto más profundo. Entre los conocidos mutuos, cuando su figura salía y sale a colación, aun con la tristeza de ahora por haberlo perdido, la reacción unánime era y es de admiración, respeto y simpatía a partes iguales.

Su altura intelectual, su personalidad y empuje, la capacidad y el ánimo para el trabajo, la creatividad en los enfoques, el rigor en el análisis, sus dotes para la comunicación y la brillantez de su oratoria sin dejar nunca de llamar a las cosas por su nombre, la cercanía en el trato, la cordialidad y el buen humor, su benevolencia habitual y el rigor justo cuando éste debía emplearse, hacían del profesor Gonzalo Borrás un referente en todos los sentidos.

Al releer en estas semanas -a modo de sentido y callado tributo- varios de sus trabajos que como un tesoro guardo en la biblioteca, algunos dedicados más por su generosi- 
dad que por merecimiento propio, no puedo dejar de pensar en la deuda de gratitud que -como yo- tantos de nosotros, dentro y fuera de la comunidad universitaria, tenemos contraída con su figura.

El más sentido pésame a su mujer Marisol, tan entrañable como él, a sus hijos y a toda su familia, a sus amigos, sus discípulos y colegas del departamento de Historia del Arte de la Universidad de Zaragoza y del resto de institucio- nes y universidades en las que, como la de Málaga, se prodigaba felizmente y donde tanto saber y magnífico recuerdo dejó, y en definitiva también a todos los que amamos esta disciplina, al mundo universitario y de la investigación, y en general de la cultura, porque hemos perdido a un maestro, un sabio y un ser humano excepcional.

Javier Ordóñez Vergara

\section{Bibliografía}

ÁlVARO ZAMORA, M. ${ }^{a}$ Isabel, LOMBA SERRANO, Concepción y PANO GRACIA, José Luis (coords) (2013), Estudios de historia del arte. Libro homenaje a Gonzalo M. Borrás Gualis, Institución Fernando el Católico, Zaragoza. 